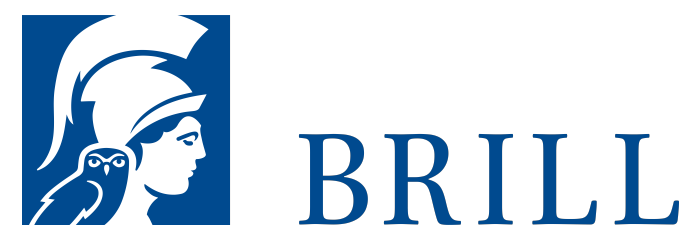

\title{
Moralisches Wissen
}

Grundriss einer reliabilistischen Moralepistemologie

Author:Jan-Hendrik Heinrichs

Dieses Buch untersucht die Art und Weise, wie wir zu gerechtfertigten moralischen Überzeugungen kommen. Moralische Überzeugungen werden in ähnlicher Weise gebildet und gerechtfertigt wie nicht-moralische. Daher können Erkenntnisse über epistemische Rechtfertigung auch helfen, ethische Rechtfertigung zu erklären. Ethische Rechtfertigung wird als der Versuch verstanden, in moralischen Fragen richtige Antworten zu finden, also moralische Erkenntnis zu gewinnen. Auf der Suche nach richtigen Antworten ist es in der Ethik wie in jeder anderen Disziplin am besten, sich zuverlässiger Verfahren zu bedienen. Mit dem Begriff eines zuverlässigen Verfahrens werden sowohl die axiomatisch-deduktiven Rechtfertigungsverfahren der rationalistischen Tradition als auch die induktiven, abduktiven und probabilistischen Gegenmodelle des Empirismus als gleichberechtigte Bestandteile ethischer Rechtfertigung behandelt. Welche Verfahren zuverlässig sind, lässt sich durch den Abgleich der Methodenapparate unterschiedlicher Disziplinen entscheiden. Exemplarisch werden einige Verfahren der rationalistischen wie auch der empiristischen Ethik auf Ihre Eignung als zuverlässige Verfahren evaluiert.

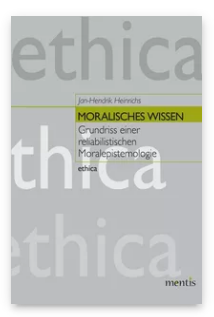

Pages: 208

Seiten

Language:

German

Subjects:

General,

Philosophy

Publisher: Brill | mentis

Series:

ethica, Volume:

23

E-Book (PDF)

Released online:

o1 Feb 2013

ISBN: 978-3-

89785-865-7

List price

Paperback

Publication date:

o1 Feb 2013

ISBN: 978-3-

89785-318-8

List price 
For more information see brill.com

Order information: Order online at brill.com +44330 333 0049 | customerservices@brill.com Submission information: brill.com/authors

Titles published by Brill | Fink, Brill | mentis or Brill | Schöningh: +49(o)715413279216| brill@brocom.de 